\section{Real-time Monitoring of Greenhouse Climate Control Using the Internet}

\author{
Niels Ehler and \\ Jesper M. Aaslyng
}

Additional IndeX wORds. environmental control computer, HTML, databases, dynamical web integration

Summary. The possibility of constructing an Internet application that would enable greenhouse users to track climate and control parameters from any Internet-connected computer was investigated. By constructing a set of HTML-templates, dynamic information from the control-system databases was integrated in real-time, and was uploaded to a common net-server by automatic generation of web pages using software developed during the project. Good performance, reliability and security were obtained and the technology proved to be an efficient way of supplying a broad range of users not only with climatic data but also with results from ongoing research.

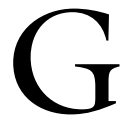
reenhouse climate control traditionally has been a topic where process regulation has been the main focus. The introduction of computers and digital technology in the early 1980s has greatly improved the control possibilities and significantly increased the amount of data acquired by standard greenhouse operations (Hashimoto et al., 1980; Udink ten Cate and Challa,

Section for Horticulture, Department of Agricultural Sciences, The Royal Veterinary and Agricultural University, Thorvaldsensvej 57, DK 1871 Frederiksberg C, Denmark. The cost of publishing this paper was defrayed in part by the payment of page charges. Under postal regulations, this paper therefore must be hereby marked advertisement solely to indicate this fact.

The authors thank Allan Holm Nielsen for his invaluable assistance in designing the graphical elements integrated in the web application described in this paper.

Hortlechnology • October-December 2001 11(4)
1984). One of the most challenging tasks of the modern greenhouse grower is to manage the large amount of data volume and to process it in such a way that important information is not overlooked because of an overload of the available data (Ehler and Rystedt, 1990). This makes information management an important area of research and development in greenhouse environmental control. Once the significant information has been identified and retrieved, it may be necessary to provide a broad range of users a simple way of accessing these data. The Internet is an obvious candidate as a channel for distributing this information. So far data access for greenhouse computers has only been possible using remote access software packages, but this requires installing of licensed software on both the client and the server PC.

If greenhouse information can be directed to a web site, then any person, regardless of having special technical skills, can gain access with a standard Internet browser. The greenhouse is a dynamic system where important system states change every few minutes. Therefore it is necessary that the contents of the web site should be automatically updated on a similar time-scale, to provide the user with the current climate and status of the technical systems. In the European green-

house industry the number of hightech greenhouse operations is constantly increasing. It is becoming increasingly important to monitor the system $24 \mathrm{~h}$ per day by a wider range of people who have an interest in the information. In university greenhouse operations, researchers and students alike are interested in closely following the experiments, but without having to be physically present all the time. Furthermore, the general public might also have an interest in climatic information, not just from inside the greenhouses but also from the weather station connected to the climate computer system and from ongoing research.

The objective of the project was to develop a system that could dynamically generate a web application to integrate real-time greenhouse control information. The web site should work reliably to supply greenhouse users with continuous climatic information. The site should enable the user to quickly gain access to the most critical data describing the greenhouse climate and the status of the control functions. Furthermore, the application should be readily tailored to suit

Fig. 1. Outline of the total system structure showing the different system components and how they relate to each other.

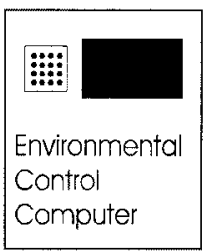

$\Delta$

Environmental Information
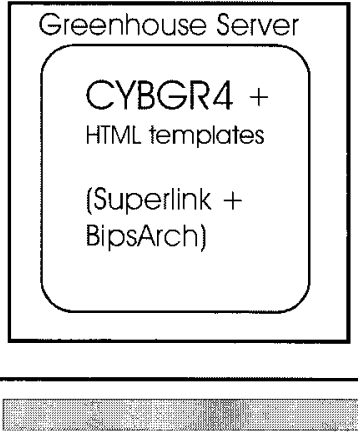

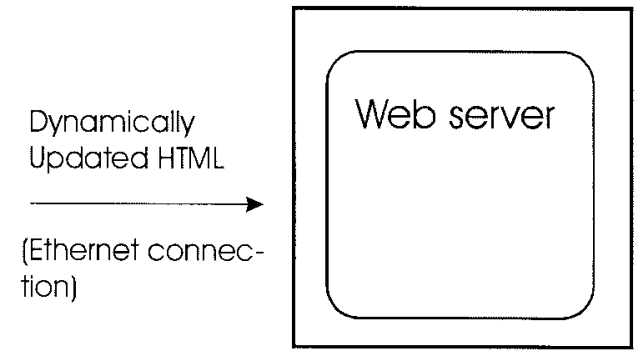

Sensor signals \& Set point changes

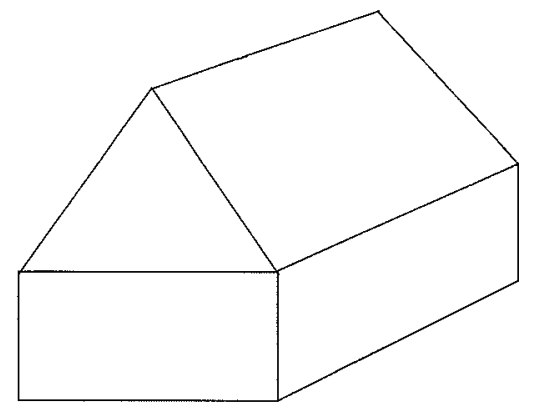

4

Updated HTML

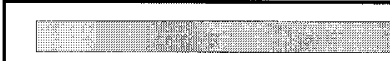



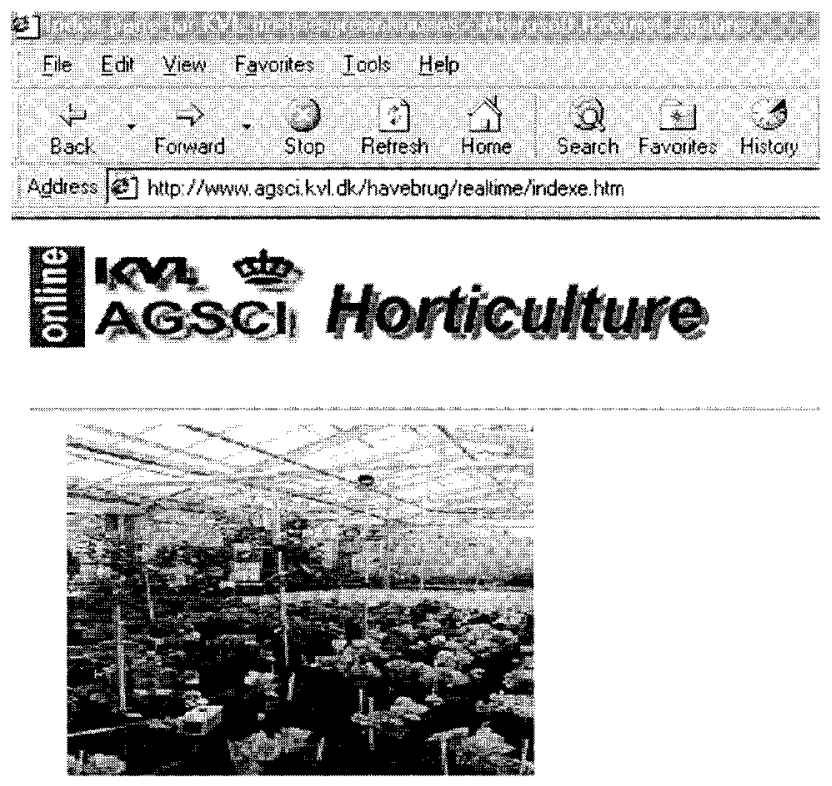

The weather at KVL:

Temperature: $15.7^{\circ} \mathrm{C}$

Irradiance 752.1 micromolim2 $*_{s}$

Wind speed $0.3 \mathrm{~m} / \mathrm{s}$

Rain indicator: 0.0 ( $0=\mathrm{N}$ o rain, $1=\mathrm{Its}$ raining)

Last 24 hour MAXIMUM-temperature: $16.6^{\circ} \mathrm{C}$

Last 24 hour MIINIMUM-temperature: $9.4^{\circ} \mathrm{C}$

Last 24 hour MAXIMUM wind speed: $6.9 \mathrm{~m} / \mathrm{s}$

Last 24 hour accumulated irradiance: $9297.7 \mathrm{Micromolm2}$

Last updated: $\quad 28-06-001054: 02$

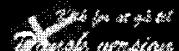

Visit our ereenhouses

Microsoft Windows 95 operating system and the DGTVolmatic ECC-standard software Superlink (DGTVolmatic, 1988). Superlink included a standard application interface, described by Ehler (1991). This application interface was used for running a database application BipsArch, which was developed by the project. BipsArch can connect to any climate computer system through a well-defined, vendor-specific device driver, which reflects the structure of the used climate computer system. BipsArch continually updates a set of Paradox databases (Borland International, 1992) with greenhouse information every 10 min, effectively creating a virtual greenhouse. These databases serve as a

Fig. 2. The main welcome screen of the greenhouse web application.

specific information needs arising from, for instance, demands made by ongoing experiments.

\section{Materials and methods}

System overview. The overall structure of the system, which was implemented at the greenhouse complex of the Royal Agricultural University of Copenhagen is shown in Fig. 1. Twenty greenhouse compartments were controlled by an environmental control computer system (ECC) supplied by the DGT-Volmatic A/S Corporation (Brøndby Strand, Denmark). This system consists of seven LCC1200-microcomputers (DGTVolmatic, 1988) which function as climate registration and regulation computers. They are connected to a supervising $\mathrm{PC}$ - the greenhouse server-in real-time using an RS232 interface. The software used were the shared common and generic information pool and standard interface for any greenhouse application that needs to access climate information or needs to update the set points of the ECC. BipsArch was developed using the Borland Delphi 3.0 (Borland International, 1997) programming language.

The greenhouse server also ran the web site generation software (CYBGR4) developed by the project. CYBGR4 was responsible for generating the necessary HTML-pages and uploading them to the university webserver, using a simple FTP protocol via an Ethernet connection.

Structure and FUnction OF THE WEB-APPLICATION GENERATOR PROGRAM CYBGR4. The main tasks of this program were to access the necessary data from the greenhouse standard databases and then integrate these into HTML code for the web application. However, it was first necessary to ensure that the standard databases contained the desired information. This was done by sending a request to BipsArch, the greenhouse server program to begin collecting the data from the climate computer system needed by the web application.

The web-application program (CYBGR4) processed a list of all the web pages needed for the application. Each page is represented as a text file containing HTML coding, which functioned as a template for the page shown on the Internet. On a given page certain locations were selected to contain the variable information from the greenhouse compartments. Any observation is given a specific name in the standard database to distinguish it from any other observation. For instance, the air temperature was assigned the identifier name TmpAir. The system then scans the database for the given combination of compartment number and input name and retrieves the desired record that contains all the data for the given observation, such as the observation value and the time and the date, when the observation was performed.

CYBGR4 parsed the text file and converted the values into standardHTML code which can be shown by any browser. The new HTML file with the dynamic data was then written to the local disk. When all the new pages had been generated, they were uploaded to the university's common web-server. To cater for special information that was not part of the normal environmental computer system, CYBGR4 also had the ability to generate new information by processing the typical environmental data, for example the maximum temperature of the last 24 -h period. This was calculated based on the contents of the standard databases. The result was returned to the common database, thus supplying new information which could be used by other applications running on the greenhouse server.

\section{Results and discussion}

Structure AND contents OF THE WEB APPLICATION. The main structure consisted of a welcome screen (<http://www.agsci.kvl.dk/ havebrug/realtime/indexe.htm>) which was linked to a map of the total greenhouse operation. From the map, the user gained access to the data from any greenhouse compartment by clicking on the relevant part of the map. 


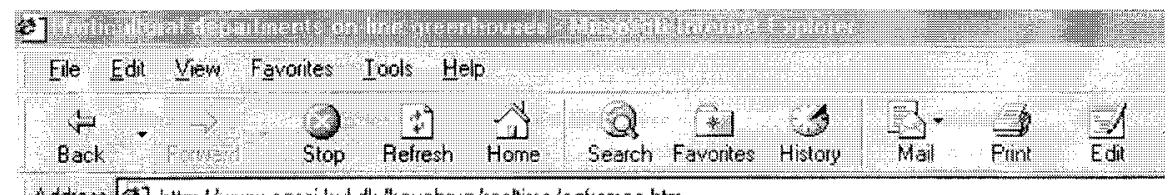

sdores: ed hitp//www agscikwldk havebug/reatime/cgltamee htm

\section{INGSeil Honticulture}
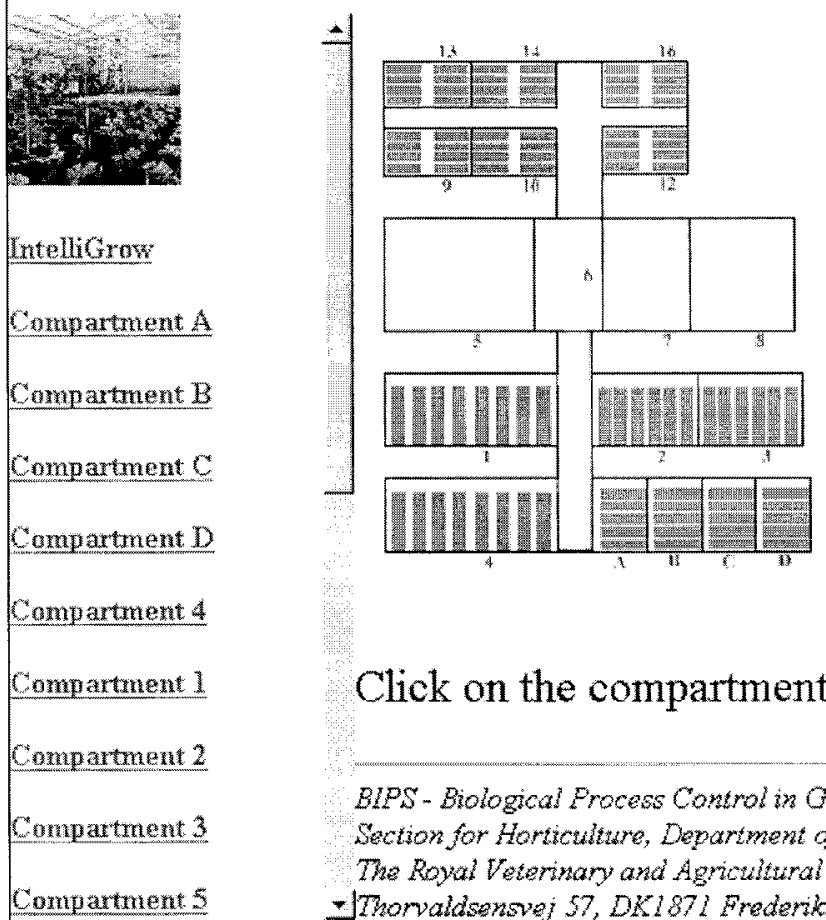

\section{Click on the compartment you want to visit}

BIPS-Biological Process Control in Orewnouses.

Sowtion for Horticulure, Department of Agriculural Soincess.

The Royal Veterinary and Agncultumal Uniwersty. - Thorvaldsensvei $57,0 K 1871$ Frederiksberg C, Denmark

Fig. 3. Clickable map depicting the layout of the total greenhouse operation of the agricultural university.

The main welcome screen (Fig. 2) was a simple web page consisting of an image from the greenhouses and data from the weather station. The page showed real-time climate data and calculated values such as the minimum and maximum outside temperature from the last 24-hour period. These data were popular not only with the employees at the university but with private gardeners who use the information in their plant-growing practices. The main web page of The Royal Veterinary and Agricultural University (<http:// www.kvl.dk>) has a direct link to this page. The page also contained a short description of the activities in the greenhouses and contact information for user feedback. Access to the greenhouse data could be obtained by clicking on either the visit link or on the main greenhouse image. The user can also here choose between a Danish and an English language version of the web site.

The next screen (Fig. 3) is a map depicting the layout of the total greenhouse operation and is a more complex web page, using frames. The page consisted of two sections: one included a menu with the names of all the connected greenhouse compartments, the other section was the actual map. The user could select the area from which to view data, either through the text menu or by pointing at the map. This gave access to data from the selected compartment, which was then shown in the frame previously occupied by the map. The general compartment page (Fig. 4) showed a still picture from the greenhouse and a list of the 16 most important climatic and regulatory parameters (Table 1). The computer system has approximately 400 different readings (sensor readings, set points, actuator states and so forth), therefore it is important to focus on a few essential data values to simplify the monitoring task.
The same data were shown for all compartments, but new information could readily be added to a given page. All that was needed was to add the relevant BipArch code to the HTML template and if necessary add these data to the greenhouse standard database. This only called for one new line of code in the program. From the compartment page the user could either choose another compartment through the menu buttons on left side of the screen, or return to the site map by clicking on the picture at the top of the menu.

Performance and stability were considered as the highest priority. The web page generation system was located in an integral part of the greenhouse server. This could affect performance as the server needed to run efficiently so that all the other parts of the control systems for the greenhouses were not impaired in any way. The most important factors affecting performance were the size of the database, access methods for the database, parsing-algorithms for analyzing the HTML templates, and uploading methods for transferring the generated pages to the web-server. To minimize the size of the database only the most current measurements for the mostimportant sensor observations were included. Exceptions to this rule were the weather-station observations, including air temperature, wind speed, and irradiance which were kept for a week to enable calculations of extremes and sums. Another important issue was the opening and closing routines for the Paradox database system. The closing operation was especially time consuming. To improve the performance, the access methods were modified in such a way that the database was only opened and closed once for every compartment per cycle. Initially this process required three minutes to generate the twenty web pages, primarily because of the parsing algorithm. A new standard string search routine from the Systools package (TurbopowerSoftware, 1996) dramatically improved the performance. Currently the system generates more than 40 web pages, using approximately $30 \mathrm{~s}$ for the total operation which include database updates, calculations of climate extremes and uploading to the Web server.

The upload procedure was another critical factor affecting performance, as direct write operations from the greenhouse server to the web server were very sensitive, because the network connec- 


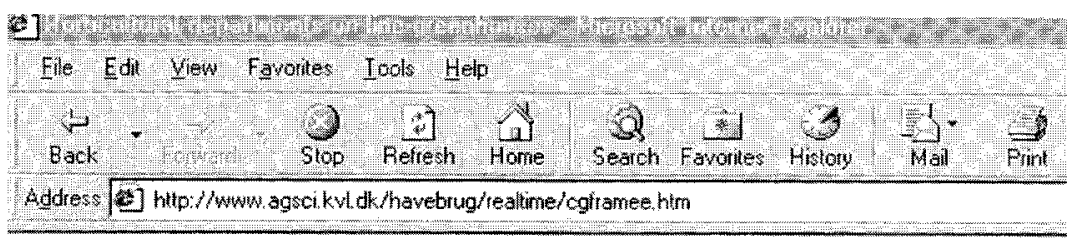

\section{IAGsei Honticulture}

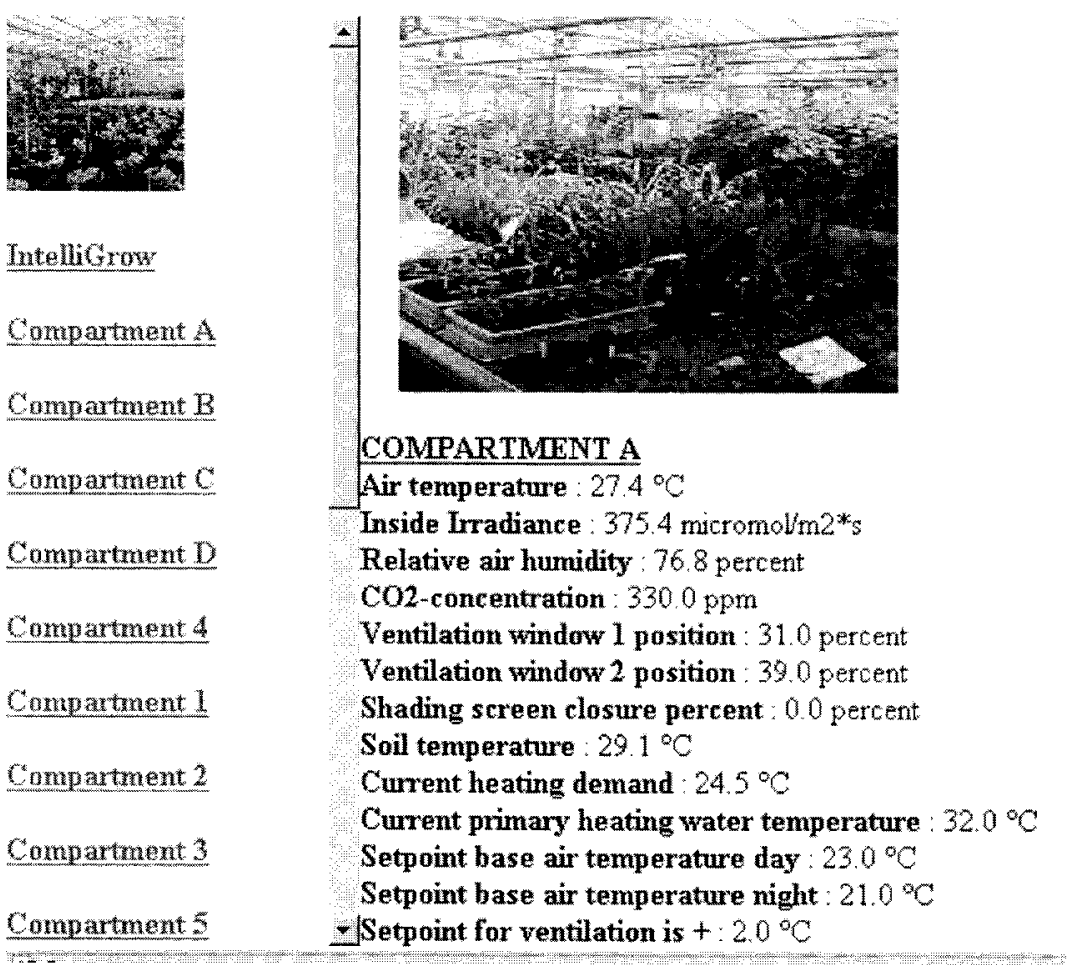

Fig. 4. An example of a standard web page containing real-time data from a greenhouse compartment.

tion between the two servers needed to be open all the time. As an alternative all files were uploaded in one single step using the FTP protocol, where it was possible to integrate error-trapping into the CYBGR4 software. This enabled the application to avoid transmitting files, when network problems made this impossible.

The system has been fully operational for more than 2 years and the stability has been very good as we have only experienced about $10 \mathrm{~d}$ of down time. The main problems concerning stability were system errors in other applications running on the greenhouse server, and general network problems which sometimes afflict the university network as a whole. On some occasions it was also necessary to rebuild the databases, which are sensitive to system crashes. In order to take this into con- sideration, much work was spent on modifying the CYBGR4 code to make it more independent of the above-mentioned events.

It would have been a simple matter also to use the application for changing the set points of the climate controls. For security reasons we chose not to do this in order to prevent unauthorized users or hackers from interrupting or even destroying important research activities.

A mere encrypted password protection would not be sufficiently safe, but an implementation of an electronic signature as used by for instance banking web sites could be integrated in the system but would require major restruction of the software. With this level of security it would be a very convenient way of programming the greenhouse control system, especially as this could be done from any Internetconnected computer anywhere in the world. This also leads to consideration of the idea of changing the user interface of the ECCs to using a browser-based technology for monitoring and controlling plant growth and climate.

This type of application is also an efficient tool for speedily distributing research information to growers and the public. To demonstrate this, a complex energy-saving and production-optimizing control system called IntelliGrow (Royal Veterinary and Agricultural University, 2000) also was integrated with CYBGR4. CYBGR4 was used for uploading dynamically generated graphs depicting the energy consumption in different compartments and giving many new persons the ability to follow the results of the research as it progresses from day to day.

\section{Conclusions and future aspects}

Based on the experiences with the CYBGR4 system, it was concluded that it was possible to construct and implement web-driven systems that were easy to operate and which could supply relevant information to a wide range of different users interested in dynamic climate and process data from greenhouses. The application proved easy to maintain and stable in operation. Furthermore, it was concluded that this sort of control system interface provided many new possibilities for adding functionality to the greenhouse control system. It would, for instance, be simple

Table 1. The climate data and set points included in the standard greenhouse compartment page layout.

Data from environmental control computer

Air temperature

Inside irradiance

Relative air humidity

$\mathrm{CO}_{2}$-concentration

Ventilation window 1 position

Ventilation window 2 position

Shading screen closure percent

Soil temperature

Current heating demand

Current heating water temperature

Set point air temperature day

Set point air temperature night

Set point ventilation

Set point shading screen

Set point soil temperature day

Set point soil temperature night 
to add E-mails or Short-Message-System alarms which could be routed to the responsible person, regardless of his physical location. The importance of this could be increased significantly in the near future, with the proliferation of wireless handheld communicators and cellular telephones using wireless access to the Internet (WAP telephones).

The software technology here is rather simple to implement and the source code is available for academic purposes by contact to the authors. Before using this software, it would be necessary to establish routines for realtime communication with the ECC, for instance by using the BipsArch system and writing a device driver for the current type of ECC.

\section{Literature cited}

Borland International. 1992. Paradox user's guide. Borland Intl., Inc., Scotts Valley, Calif.

Borland International. 1997. Delphi 3 user's guide. Borland Intl., Inc., Scotts Valley, Calif.

DGT-Volmatic. 1988. DGT-Volmatic Klimacomputer LCC1240, Technical manual. DGT-Volmatic A/S Corp., Brøndby Strand, Denmark.
Ehler, N., 1991. Interfacing crop models to standard software for greenhouse climate control. Ecol. Modeling 56:245-257.

Ehler, N. and J. Rystedt. 1990. From regulation automat to information management system: An analysis of the use and potential of the climate computer in greenhouse production. Proc. 3rd Intl. Conf. Computers in Agr. Ext. Prog. 1:82-94:

Ehler, N. and J.M. Aaslyng. 2001. Intelligrow: Integration with a generic greenhouse environmental control computer using the BipsArch concept. Environmental Modelling Software (In press).

Hashimoto, Y., T. Morimoto, and S. Funada. 1980. Computer processing of speaking plant for climate control and computer aided plantation. Acta Horticulturae 115: 317325 .

Royal Veterinary and Agricultural University. 2000. IntelliGrow. Royal Vet. Agr. Univ., Dept. Agr. Sci., Hort. Sec., Copenhagen, Denmark. 11 Oct. 2000. <http://www.agsci.kvl.dk/havebrug/ intelligrow $>$.

Turbopower Software. 1996. Systools user's manual. Turbopower Software Co., Colo. Springs, Colo.

Udink ten Cate, A.J. and H. Challa. 1984. On optimal computer control of the crop growth system. Acta Hort. 148: 267-276. 